\title{
THE INFLUENCE OF ECOLOGICAL THEORY IN CHILD AND YOUTH CARE: A REVIEW OF THE LITERATURE
}

\author{
Teri Derksen
}

\begin{abstract}
The purpose of this literature review is to explicate the meaning of ecological theory and trace its influence in Child and Youth Care. The review focuses on the work of Urie Bronfenbrenner and explores how his early ideas have resonated through descriptions of the field, in efforts to prepare practitioners for professional practice, and in actual practice itself. The review concludes by questioning how Bronfenbrenner's work could continue to inform Child and Youth Care practice, particularly in the areas of policy and community work.
\end{abstract}

Since the 1990s, efforts have been made across North America to define, formalize, and professionalize Child and Youth Care practice in North America (Krueger, 2002; Mattingly, Stuart, \& VanderVen, 2002). One of the key initiatives in these efforts has been the North American Certification Project or NACP (Mattingly et al., 2002) that identifies foundational attitudes for Child and Youth Care professionals and defines necessary competencies in the following five domains for professional practice: professionalism; cultural and human diversity; applied human development; relationship and communication; and developmental practice methods. Within the applied human development competency domain, emphasis is placed on Child and Youth Care practitioners being "... well versed in current research and theory in human development with an emphasis on a developmental-ecological perspective" (Mattingly et al., 2002).

Ecological theory, in particular the pioneering work of Urie Bronfenbrenner, has been influential in the field of Child and Youth Care. Ecological theory not only has deep and far reaching roots in the field, but also has the potential to influence new directions and development in Child and Youth Care. The goal of this literature review is to investigate the vital link between ecological theory and Child and Youth Care. The review explores the following questions: (a) What is ecological theory?; and (b) How has ecological theory influenced Child and Youth Care Practice? It also challenges us to consider the ways in which ecological theory could continue to influence Child and Youth Care practice particularly in the areas of policy and community-based work.

\section{Literature Search}

This literature review was conducted using The University of Victoria's databases Academic Search Primer, ERIC, Psych Info, Social Work Abstracts, Web of Science, Social Service Abstracts, Psychology, Psych Articles and Sociology. In addition, Google 
Scholar and the table of contents from 1998 to 2008 for the journals Child and Youth Care Services and Child \& Youth Care Forum were searched. Key phrases such as Ecology of Human Development, Ecological Theory, and Child and Youth Care and key words such as Bronfenbrenner, Children, Family, and Community were used. In the event of unwieldy search results, searches are normally limited to the last eight years. However, given the significant emergence of ecological theory in the 1970s limiting searches in this way was avoided. Although Child and Youth Care draws on knowledge from many disciplines, efforts were made to include only literature specific to Child and Youth Care, the subject that is the focus of this paper. Search results identified a number of texts and in these cases individual chapters were used in addition to peer-reviewed articles.

\section{What is Ecological Theory?}

\section{Historical Context}

According to Tudge, Gray, and Hogan (1997), the term ecology was coined in 1873 by Ernest Haeckel, a German zoologist and evolutionist. Tudge et al. (1997) define ecology as, "...the study of organism-environment interrelatedness" (p. 73), and although the term originated in biology other disciplines such as geography, sociology, anthropology, and economics have incorporated ecological approaches. The origins of the study of human development in relation to the environment can be traced to Schwabe and Bartholomai's research of neighourhood influences on children's development in Germany in the 1870s (Tudge et al., 1997). Tudge and colleagues go on to acknowledge that many scholars since that time have contributed to the development of ecological and contextual approaches to human development but that the perspectives of these scholars have "...never been at the forefront of psychology" (p. 75).

Indeed what Tudge et al. (1997) and Cole (1979) point out is that ecological approaches, which were more descriptive in nature to understanding human development, emerged in a scientific climate that was attempting to explain human behaviour through quantitative empirical reductionist experiments. As Cole (1979) states, "What has been lost in our textbook accounts of the history of psychology is the fact that a great many other scholars who were around when psychology embraced the laboratory were not especially moved by the new enterprise" (p. vii). This dichotomy between descriptive and explanatory psychology had scholars from both movements in the early 20th century engaged in discussions of the "crises" in psychology (Cole, 1979; Tudge et al., 1997). According to Cole (1979), Urie Bronfenbrenner was one of a small group of scholars dedicated to overcoming this "crisis" and developing "... a discipline that is both experimental and descriptive of our lives as we know them" (p. ix).

Bronfenbrenner (1979) condemned developmental psychology of the time as "...the science of the strange behavior of children in strange situations with strange adults for the briefest possible periods of time" (p. 19). Bronfenbrenner has been described as a pioneer who has made outstanding contributions and influenced the work and writing of many scholars in the study of the ecology of human development (Barnes, Katz, Korbin, \& O’Brien, 2006; Brendtro, 2006; Cole, 1979; Moen, 1995; Pence, 1988; Lerner, 2005). 
Bronfenbrenner's work has also been influential in the field of Child and Youth Care and it is this influence that will be the focus of the remainder of this paper.

\section{Bronfenbrenner - An Introduction}

Bronfenbrenner $(1979,1995)$ points out that it was his experiences growing up on the premises of a state institution in upstate New York, situated on over 3,000 acres of farmland and natural landscapes that planted the seeds for his ecological concepts of human development. His father, a neuropathologist with both a medical degree and a Ph.D. in zoology, was a significant influence as Bronfenbrenner (1979) states his father "...would alert my unobservant eyes to the workings of nature by pointing to the functional interdependence between living organisms and their surroundings" (p. xii). His mother was also an influence as he recounts memories of his early childhood in Russia where his mother would speak reverentially of "great psychologists" (Bronfenbrenner, 1995, p. 600). Later in life, Bronfenbrenner (1979) credits his work in cross-cultural contexts such as small rural communities in the U.S., Canada, western and eastern Europe, the U.S.S.R., Israel, and the People's Republic of China as influential in two significant ways. First, by examining lives in these various cultural contexts he witnessed different environments producing differences in human nature, as he states "...the process and product of making human beings human clearly varied by place and time" (Bronfenbrenner, 1979, p. xiii). Second, work in these various cultural contexts drew his attention to the ways in which public policies created particular living conditions, which ultimately influenced human development.

Bronfenbrenner went on to become Professor Emeritus of Human Development and Psychology at Cornell University and a child psychologist who was world-renowned and highly respected (Brendtro, 2006; Lerner, 2005). In 1994, Cornell University's College of Human Ecology Life Course Center was renamed the Bronfenbrenner Life Course Center in his honour (Cornell University College of Human Ecology, 2009). Bronfenbrenner was honoured by the American Psychological Association in 1993 as one of the world's most distinguished scientists. He coauthored, authored, or edited over 300 articles or chapters and 14 books. In addition, he co-founded the Head Start program in the United States, an early intervention program designed to prepare children for school success (Brendtro, 2006; VanderVen, 2006). Brendtro (2006) observes that “...before Bronfenbrenner, psychologists, sociologists, educators, anthropologists, and other specialists all studied narrow aspects of the child's world" (p. 163).

Bronfenbrenner's ecology of human development ties together and acknowledges aspects of all of these fields of study with human development in context at its core (Brendtro, 2006, Bronfenbrenner, 1979). As Bronfenbrenner (1979) states, "The ecology of human development lies at a point of convergence among the disciplines of the biological, psychological, and social sciences as they bear on the evolution of the individual in society" (p. 13). Urie Bronfenbrenner died in 2005. 


\section{From an Ecology of Human Development to a Bioecological Paradigm - An Overview}

The contributions of Urie Bronfenbrenner span over 60 years (Lerner, 2005), with some of the basic ideas of his ecological theory traced back to a series of articles written in the 1940s (R. B. Cairns \& B. D. Cairns, 1995; Bronfenbrenner, 1995). By the 1970s, Bronfenbrenner began to explicitly articulate his model for understanding human development as the "ecology of human development" or "development in context" (Bronfenbrenner, 1988). He declares that although he is often credited as the originator of this perspective, he is not. Rather, he acknowledges the influence of many scholars such as Kurt Lewin, Lev Vygotsky, George Herbert Mead, Jean Piaget, Sigmund Freud, and others and suggests that the significance of his contribution is the manner in which he conceptualized these ideas in a systemic form (Bronfenbrenner, 1979, 1988). This "...new theoretical perspective for research in human development" (Bronfenbrenner, 1979, p. 3), is outlined in his groundbreaking book, The Ecology of Human Development: Experiments by Nature and Design, which was published in 1979 and is "considered by all scholars of human development a watershed contribution to the understanding of human ontogeny" (Lerner, 2005, p. xiii).

The notion that development was influenced by the environment was familiar and commonplace in science at the time according to Bronfenbrenner (1979). However, he argued that despite this common understanding little attention was paid to research and theory on environmental influences on human development. Bronfenbrenner's theoretical perspective was new in the way in which it conceptualized the developing person, the environment, and the interaction between the two. As Bronfenbrenner (1979) states, there "...is a marked asymmetry, a hypertrophy of theory and research focusing on the properties of the person and only the most rudimentary conception and characterization of the environment in which the person is found" (p. 16). He further offered a solution to this asymmetry through his theoretical perspective of the ecology of human development defined as:

The ecology of human development involves the scientific study of the progressive, mutual accommodation between an active growing human being and the changing properties of the immediate settings in which the developing person lives, as this process is affected by relations between these setting, and by the larger contexts in which the settings are embedded. (p. 21)

Bronfenbrenner (1979) conceptualized the settings and larger contexts in which the settings are embedded as a set of nested structures or systems, with the microsystem defined as "... a pattern of activities, roles, and interpersonal relations experienced by the developing person in a given setting with particular physical and material characteristics" (p. 22), at the innermost level. In his initial theoretical concepts, Bronfenbrenner (1979) underscores the phenomenological nature of the microsystem and all the levels within the ecological model, when he points out the significance of the environment as it is perceived by the developing person as what matters for development and behaviour. 
In his subsequent writings, Bronfenbrenner (1988) points out that his earlier emphasis on the significance of the phenomenological nature of development neglected salient objective conditions and events occurring in the developing person's life. He highlights the significance of belief systems actualized in the behaviour of individuals as they interact, cope, confront, alter, and create the objective conditions and events in their lives. This shift in thinking is evident when Bronfenbrenner (1979) adds to Thomas' dictum that "If men define situations as real, they are real in their consequences" (p. 23), a companion principle to "Real situations not perceived are also real in their consequences" (Bronfenbrenner, 1988, p. xiv).

The mesosystem, which is the next level of the model and along with the microsystem has the most direct influence on the developing child, "...comprises the interrelations among two or more settings in which the developing person actively participates..." (Bronfenbrenner, 1979, p. 25). The next two levels, which have more indirect influence on the developing person, have been coined the exosystem and macrosystem. The exosystem "...refers to one or more settings that do not involve the developing person as an active participant, but in which events occur that affect, or are affected by, what happens in the setting containing the developing person"; the macrosystem "... refers to consistencies, in the form and content of lower-order systems...that exist or could exist, at the level of the subculture or the culture as a whole, along with any belief systems or ideology underlying such consistencies" (Bronfenbrenner, 1979, p. 25). Fundamental to these nested systems is the interconnectedness between them, as Bronfenbrenner (1979) argues what happens between these systems can be as influential to development as what happens within them. For example, he points out that a child's ability to learn to read will depend upon not only the lessons the child learns in school but also on the nature of the ties between the child's home and school.

It was only a few years after The Ecology of Human Development was published that Bronfenbrenner $(1988,1995)$ began to question his original theoretical concepts as outlined in the 1970s and alter his original ecological model. He was gratified at the shift he witnessed over time from experiments in "strange places" like laboratory settings to more commonplace approaches studying children in real life settings (Bronfenbrenner, 1988). Barnes et al. (2006) comment:

What has changed in the past few decades is the acknowledgement by a number of disciplines concerned with child and family development, such as psychology, sociology, anthropology, psychiatry and social policy, that parents and children occupy systems beyond the family system, that they need to be understood in context, and that their environment makes a difference to their health, well-being and progress. (p. 1)

Lerner (2005) notes that what concerned Bronfenbrenner (1988) was that the pendulum had swung too far toward context and that his original ecological framework and science at the time did not adequately examine the development of the individual. Bronfenbrenner (1995) states, "In place of too much research on development 'out of 
context', we now have a surfeit of studies on 'context without development'." (p. 616). In Bronfenbrenner's 1988 foreword to Ecological Research with Children and Families: From Concepts to Methodology, he states that his original theory was imbalanced in its emphasis on the environment to the neglect of equal emphasis on the developing organism and the result has been research that has offered "...new knowledge about the complex structure of an environment conceived in systems terms and the bidirectional processes operating both within and across its constituent subsystems" but that has, nonetheless, offered "far less new knowledge about the evolving complex structure of the developing person" (p. xvii). Lerner (2005) points out that Bronfenbrenner recognized his theory would be incomplete until he included in it the levels of individual structure and function (biology, psychology, and behaviour) "fused dynamically with the ecological systems he described" (p. xiv).

Bronfenbrenner and colleagues Ceci, Crouter, and Morris worked for over a decade to integrate the developing person into the ecological systems he first described in 1979's The Ecology of Human Development, with the result being what is now referred to as the Bioecological Model of human development (Bronfenbrenner \& Ceci, 1994; Bronfenbrenner, 2005; Lerner, 2005). Bronfenbrenner (2005) emphasizes the evolving nature of the bioecological paradigm for the study of human development and within this newly formulated model defines development as "the phenomenon of continuity and change in the biopsychological characteristics of human beings both as individuals and groups". He goes on to declare that this "...phenomenon extends over the life course across successive generations and through historical time, both past and present" (p. 3 ). Moen (1995) states that the bioecological paradigm, described as the person-processcontext-time (PPCT) model "attends to the interplay between (a) characteristics of the person and (b) the social context in affecting (c) developmental processes (d) over time" (pp. 4-5).

Despite Bronfenbrenner's prolific writing and the evolution of his original ecological paradigm to a bioecological model, the only references to Bronfenbrenner in the Child and Youth Care literature reviewed was limited to his groundbreaking 1979 book, The Ecology of Human Development: Experiments by Nature and Design. What follows is an attempt to explicate the influence of Bronfenbrenner's work in the field of Child and Youth Care.

\section{What is the Influence of Ecological Theory on Child and Youth Care?}

Within the Child and Youth Care literature reviewed the influence of Urie Bronfenbrenner's theoretical perspective on the ecology of human development is evident (Ferguson, Pence, \& Denholm, 1993a; Krueger, 2000, 2005; Maier, 1991; Mattingly et al., 2002; Phelan, 2003; Radmilovic, 2005; VanderVen 2006; White 2007). Clearly, his ideas have resonated within Child and Youth Care and based on the literature reviewed ecological influences, as conceptualized by Bronfenbrenner, can be seen in descriptions of the field, efforts to prepare practitioners for professional practice and in practice. 


\section{Ecological Influences - In Descriptions of the Field}

A developmental-ecological perspective frames Child and Youth Care practice across North America and in Europe, and is evident in widely accepted descriptions of the field (Ferguson et al., 1993a; Mattingly et al., 2002; European Bureau of the International Association of Social Educators, 2006). In North America, the following broad based description of Child and Youth Care given by Ferguson et al. (1993a) is now widely accepted (see also Krueger, 2002; Mattingly et al., 2002) and clearly incorporates key concepts from Bronfenbrenner's seminal 1979 book:

Professional Child and Youth Care practice focuses on the infant, child and adolescent, both normal and with special needs, within the context of the family, the community, and the life span. The developmental-ecological perspective emphasizes the interaction between persons and the physical and social environments, including cultural and political settings. (p. 12)

Social Educators in Europe, essentially the European counterpart to Child and Youth Care practitioners in North America, also pay particular attention to the influences of ecological context on development and attempt to integrate the community through social education. Social education is defined as, "The theory about how psychological, social and material conditions and various value orientations encourage or prevent the general development and growth, life quality and welfare of the individual or the group" (European Bureau of the International Association of Social Educators, 2006, p. 378). Across North America and within Europe, descriptions of Child and Youth Care practice are consistent with Bronfenbrenner's (1979) ecological paradigm that acknowledges the significance of varied contexts on the development of the child.

Child and Youth Care has also been conceptualized by Canadian scholars in various models such as the umbrella model, the cube model, the ecological onion model, and the web model (Ferguson et al., 1993a; White, 2007), which have to varying degrees all been influenced by Bronfenbrenner (1979). The umbrella model developed in 1993 was the first and illustrates the broad scope of Child and Youth Care practice, the various settings where Child and Youth Care practice takes place, and the various levels of training and educational programs that are available to prepare practitioners to work in the field (Ferguson et al., 1993a). The cube model was an extension of the umbrella model that depicted the three-dimensional interaction between practice settings, age and development of the target population, and core generic practice functions.

The onion model, developed in 1991 (Ferguson et al., 1993a), was the first model that explicitly drew on the work of Bronfenbrenner. Ferguson and his colleagues state the onion model "... reflects an ecological perspective, wherein consideration is given to the reciprocal interactions between human development and the multiple environments in which it occurs" (p. 9). In the onion model, Bronfenbrenner's (1979) nested interacting ecological systems were depicted as layers of an onion, with each layer representing the various systems within the child's ecology such as the family, community, and culture. The cube model is embedded in the onion model to "... show the interactions of the three 
vectors within and across a variety of systems that provide an ecological context" (Ferguson et al., 1993a, p. 10). Jennifer White in her 2007 article, Knowing, Doing and Being in Context: A Praxis-oriented Approach to Child and Youth Care, offers a web model of Child and Youth Care. White's model (2007) moves away from ecological systems being represented as concentric circles, which she argues is limiting in that it isolates contextual influences, and uses instead the metaphor of a web to "...depict the active, intersecting, embedded, shifting and asymmetrical qualities of everyday practice" (p. 241). In the web model community, political, institutional sociocultural, interpersonal, and organizational influences create a dynamic context for a praxis-based approach to Child and Youth Care practice.

Although the onion and web models are the most explicit in their use of Bronfenbrenner's (1979) ecology of human development, the models clearly illustrate the broad scope of Child and Youth Care work across various ecological contexts, the interaction and intersections between these systems, the significance Child and Youth Care workers place on contextual influences on children and youth, and the ability of practitioners to work in the child's natural environment. As Ferguson et al. (1993a) state, "the ability to move easily within and across systems is one of the unique characteristics of the child and youth care profession" (p. 11).

\section{Ecological Influences - In Preparing for Practice}

These models, which illustrate the centrality of an ecological perspective in Child and Youth Care, provide not only visual descriptions of the field but also shape curriculum within Child and Youth Care education and training. As early as 1979, the School of Child and Youth Care at the University of Victoria adopted an ecological perspective (R. Ferguson, personal communication, November 3, 2008), upon which the curriculum of the school is based (Kuehne \& Leone, 1994; Ferguson et al., 1993a).

Current accreditation and certification efforts within the field will also contribute to the continuation of an ecological perspective in Child and Youth Care. In 1990, the Child and Youth Care Education Consortium, which represents post-secondary educational institutions across North America, was formally established (Ferguson et al., 1993a) and in 1991, the British Columbia Child and Youth Care Education Consortium was formed (R. Ferguson, personal communication, November, 25, 2008). Currently, these groups are working to establish accreditation for post-secondary education programs in Child and Youth Care. In addition, as indicated earlier in the paper, core competencies for Child and Youth Care professionals across North America have been articulated and a developmental-ecological perspective has been identified as one of these core competencies (Mattingly et al., 2002). This competency document is guiding efforts to establish certification for practitioners in the field. Through these efforts at accreditation and certification, the ecological perspective will become even more deeply embedded in efforts to prepare Child and Youth Care practitioners for the field. As Ferguson, Pence, and Denholm (1993b) state, “.... an ecological perspective is central to the continuing development, understanding, and promotion of the field of child and youth care" (p. 282). 
VanderVen (2006) traces the patterns of career development in Child and Youth Care and uses Bronfenbrenner's micro, meso, exo and macro system framework to identify the skills required at each level of practice. For example, at the microsystem level, which is the child's most immediate environment, practitioners need to be highly skilled in direct caregiving, environmental design, and activity programming, to name a few (VanderVen, 2006). At the mesosystem and exosystem strata, practitioners are involved in indirect work with children and more direct work with adults. VanderVen argues that these levels require radically different skills than at the microsystem level and include policy design, organizational, coordination, financial administration, and political skills. VanderVen further suggests that work at the macrosystem level requires the ability to "...influence global attitudes and viewpoints about a culture or subculture..." and that this is accomplished by very few individuals, who have not typically started their career paths in group care of children (p. 244).

VanderVen (2006) argues that practitioners at each level are required for effective care in children's services and longevity in the field may be accomplished by facilitating personal and professional development through these levels of practice. While it is beyond the scope of this paper to conduct a thorough comparison of VanderVen's (2006) work to the NACP Competency document (Mattingly et al., 2002), it would however be interesting to explore the ways in which the skills articulated by VanderVen, especially those at the macrosystem and exosystem levels, are reflected in the NACP Competency document.

\section{Ecological Influences - In Practice}

Child and Youth Care practice requires practitioners to work within and across the varied ecological contexts that influence children and youth. Bronfenbrenner's influence on Child and Youth Care practice is evident in the ways in which practitioners navigate these varied terrains. His influence can also be seen in some of the literature on family work and research in CYC.

A key theme in the literature reviewed is the significance of interactions between children/youth and those who care for them (Bronfenbrenner, 1979; Krueger, 2000, 2002; Maier, 1991). Maier (1991) in his exploration of basic foundational concepts in Child and Youth Care practice, argues that "there is a repertoire of substantive care tasks underpinning child and youth care work" (p. 394). He traces a paradigm shift in how care is conceptualized, from care-taking to care-giving to care-interactions, which he describes as having a reciprocal nature as opposed to one directional nature as was found in earlier conceptions of care. Maier builds on this theme of reciprocity as he suggests that Child and Youth Care practice has shifted away from psychoanalytic, educational, and behavioural approaches to an "interactional/attachment orientation" which, he points out, has been influenced by "contemporary thinking" and Bronfenbrenner. Maier (1991) goes on to opine that "An interactional/attachment orientation recognizes that basic to human development is the existence of assured closeness (attachment) to another person..." and that attachment is formed through "... ordinary daily care interactions" (p. 395). 
Ferguson et al. (1993a), Krueger (2000, 2002, 2005), Phelan (2003), and White (2007) also focus our attention on the relational nature of Child and Youth Care practice and the significance of the "complex nature of daily interactions" (Krueger, 2002) in practice. Maier (1991) argues that the significance of attachment for human development is congruent with the perspectives of a number of theorists, Bronfenbrenner being one of them. Bronfenbrenner (1979) underscores the significance of reciprocal activity occurring within dyadic relationships for development and learning in the following hypothesis:

Learning and development are facilitated by the participation of the developing person in progressively more complex patterns of reciprocal activity with someone with whom that person has developed a strong and enduring emotional attachment and when the balance of power gradually shifts in favor of the developing person. (p. 60)

In practice, Bronfenbrenner's ecological paradigm has not only influenced the daily interactions between child/youth and practitioner but also the practitioner's efforts to work across the various ecological contexts that are significant in children's lives. For example, Krueger $(2000,2005)$ points out that youth workers not only directly work with youth in their environments but that their presence in other ecological contexts such as family and community can change these systems. Radmilovic (2005) acknowledges the influence of Bronfenbrenner in her argument that systemic change is necessary in order to support and sustain change in individuals. As VanderVen (2006) states, “...to significantly influence the quality of human services delivered to children requires a comprehensive ecological approach that can influence each of the environmental systems that impinge on children and affect their lives" (p. 254).

Phelan (2003) in his article on a Child and Youth Care approach to working with families suggests that Bronfenbrenner's ecological systems provide another lens to view the family and a useful tool for assisting family members in understanding what he calls "mutual influence processes" (p. 6) that occur within the microsystem and mesosystem. Clearly, Phelan (2003) has been influenced by Bronfenbrenner. However, given Bronfenbrenner's (1986) interest in the ways in which interfamilial processes are affected by extrafamilial conditions, including conditions in meso, exo and chrono systems, it is surprising that Phelan's (2003) conceptualization is limited to the microsystem and mesosystem only. It is also surprising that within the Child and Youth Care literature search, Phelan's article was the only one that emerged on family work in Child and Youth Care that referenced Bronfenbrenner.

Bronfenbrenner has also had a significant influence on research on human development, including research carried out by scholars in Child and Youth Care (Brendtro, 2006; Pence, 1988). As indicated earlier in this paper, Bronfenbrenner (1979) criticized traditional psychological research carried out in laboratories for its study of strange behaviour in strange situations with strange adults and, according to Brendtro (2006), he “...tipped the balance of the research agenda toward naturalistic studies" (p. 165). An example of Bronfenbrenner's influence on research in Child and Youth Care 
can be found in the edited volume, Ecological Research with Children and Families: From Concepts to Methodology (Pence, 1988). Pence explains that the volume emerged from the Victoria Day Care Research Project, which “... sought to better understand the impact of the interaction between care giving and family microsystems on children's development" (p xxii). Pence (1988) further points out that despite that the fact that contributions in the book are diverse in their range of interests and approaches to ecological research, they share an awareness of the interactive nature of behaviour and development in proximal and distal social systems, the complex nature of naturalistic research, and more meaningful descriptions of behaviour.

\section{Conclusions}

Ecological theory has clearly influenced Child and Youth Care practice and within the field the groundbreaking work of Urie Bronfenbrenner must be appreciated. This literature review has explored Bronfenbrenner's influence on widely accepted descriptions of the field, efforts to prepare individuals for practice, and within practice. There is much more to ecological theory than simply understanding that children are part of a nested system of ecological contexts. Ecological theory also pays particular attention to the ways in which reciprocal interactions between these systems influence development. In addition, ecological theory informs the more minute interactional and attachment formation processes that occur between children/youth and Child and Youth Care workers. The review has also revealed some of the ways in which ecological theory has influenced family work and research in Child and Youth Care.

A number of questions emerge as a result of this literature review. First, as noted earlier, the influence of Bronfenbrenner's bioecological theory, which is a more current formulation of his ecology of human development paradigm, was not evident in the Child and Youth Care literature reviewed and, as a result, the writer is left wondering how Bronfenbrenner's more recent concepts could influence the field. Second, how might Bronfenbrenner's work influence current efforts within Child and Youth Care to focus more intentionally on policy as it relates to children and youth? Given Bronfenbrenner's (1979) argument that analysis of social policy is critical in developmental research as it illuminates aspects of the environment including ideological assumptions found at the macrosystem level that are critical for human development, this question is certainly worth exploring. Finally, for Child and Youth Care practitioners working to support children, youth and families, what kind of change do we need to create in community contexts, how can we create this change, and in what ways can ecological theory inform our efforts? 


\section{References}

Barnes, J., Katz, I., Korbin, J. E., \& O’Brien, M. (2006). Children and families in communities: Theory, research, policy and practice. West Sussex, UK: John Wiley \& Sons.

Brendtro, L. K. (2006). The vision of Urie Bronfenbrenner: Adults who are crazy about kids. Reclaiming Children \& Youth, 15(3), 162-166.

Bronfenbrenner, U. (1979). The Ecology of human development: Experiments by nature and design. Cambridge, MA: Harvard University Press.

Bronfenbrenner, U. (1986). Ecology of the family as a context for human development: Research perspectives. Developmental Psychology, 22(6), 723-742.

Bronfenbrenner, U. (1988). Foreword. In A. R. Pence (Ed.), Ecological research with children and families: From concepts to methodology (pp. ix-xix). New York: Teachers College Press.

Bronfenbrenner, U. (1995). The bioecological model from a life course perspective: Reflections of a participant observer. In P. Moen, G. H. Elder, \& K. Luscher (Eds.), Examining lives in context: Perspectives on the ecology of human development (pp. 599-618). Washington, DC: American Psychological Association.

Bronfenbrenner, U. (2005). On the nature of bioecological theory and research. In U. Bronfenbrenner (Ed.), Making human beings human: Bioecological perspectives on human development (pp. 1-15). Thousand Oaks, CA: Sage Publications.

Bronfenbrenner, U., \& Ceci, S. J. (1994). Nature-nurture reconceptualized in developmental perspective: A bio-ecological model. Psychological Review, 101(4), 568-586.

Cairns, R. B., \& Cairns, B. D. (1995). Social ecology over time and space. In P. Moen, G. H. Elder, \& K. Luscher (Eds.), Examining lives in context: Perspectives on the ecology of human development (pp. 397-492). Washington, DC: American Psychological Association.

Cole, M. (1979). Preface. In U. Bronfenbrenner, The Ecology of human development: Experiments by nature and design. Cambridge, MA: Harvard University Press.

Cornell University College of Human Ecology. (2009). Retrieved February 14, 2009, from http://www.human.cornell.edu/che/BLCC/About/People/urie.cfm 
European Bureau of the International Association of Social Educators. (2006). A common platform for social educators in Europe. Child \& Youth Care Forum, 35(56), 375-389.

Ferguson, R., Pence, A., \& Denholm, C. (1993a). The scope of child and youth care in Canada. In R. Ferguson, A. Pence, \& C. Denholm (Eds.), Professional child and youth care (2nd ed., pp. 3-14). Vancouver: University of British Columbia Press.

Ferguson, R., Pence, A., \& Denholm, C. (1993b).The future of child and youth care in Canada. In R. Ferguson, A. Pence, \& C. Denholm (Eds.), Professional child and youth care (2nd ed., pp. 276-290). Vancouver: University of British Columbia Press.

Krueger, M. (2000). Presence, fear, curiosity, and other themes in community youth work. Applied Developmental Science, 4(1), 21-27.

Krueger, M (2002). A further review of the development of the child and youth care profession in the United States. Child \& Youth Care Forum, 31(1), 13-26.

Krueger, M. (2005). Four themes in youth work practice. Journal of Community Psychology, 33(1), 21-29.

Kuehne, V. S., \& Leone, L. (1994). A framework and process for educating students to apply developmental theory in child and youth care practice. Child \& Youth Care Forum, 23(5), 339-355.

Lerner, R. M. (2005). Urie Bronfenbrenner: Career contributions of the consummate developmental scientist (Foreword). In U. Bronfenbrenner (Ed.), Making human beings human: Bioecological perspectives on human development (pp. ix-xxvi). Thousand Oaks, CA: Sage Publications.

Maier, H. W. (1991). An exploration of the substance of child and youth care practice. Child \& Youth Care Forum, 20(6), 393-411.

Mattingly, M., Stuart, C., \& VanderVen, K. (2002). Competencies for professional child and youth work practitioners. Journal of Child and Youth Care Work, 17, 16-49.

Moen, P. (1995). Introduction. In P. Moen, G. H. Elder, \& K. Luscher (Eds.), Examining lives in context: Perspectives on the ecology of human development (pp. 1-11). Washington, DC: American Psychological Association.

Pence, A. (1988). Conclusion. In A. R. Pence (Ed.), Ecological research with children and families: From concepts to methodology (pp. 222-226). New York: Teachers College Press.

Phelan, J. (2003). Child and youth care family support work. Child and Youth Services, 25(1-2), 67-77. 
Radmilovic, S. (2005). The capacity to change and child and youth care practice: A program example and framework. Child \& Youth Care Forum, 34(2), 127-139.

Tudge, J., Gray, J. T., \& Hogan, D. M. (1997). Ecological perspectives in human development: A comparison of Gibson and Bronfenbrenner. In J. Tudge, M. J. Shanahan, \& J. Valsiner (Eds.), Comparisons in human development: Understanding time and context. Cambridge, UK: Cambridge University Press.

VanderVen, K. D. (2006). Patterns of career development in child and youth care. Child and Youth Services, 28(1/2), 231-257.

White, J. (2007). Knowing, doing and being in context: A praxis-oriented approach to child and youth care. Child \& Youth Care Forum, 36(5), 225-244.

Teri Derksen has been a Child and Youth Care practitioner since 1986. She has worked, primarily with adolescents, as a front-line worker, program administrator and community development worker in the non-profit sector and in municipal recreation and social planning. She is currently completing her M.A. in Child and Youth Care and working as a Sessional Instructor with the School of Child and Youth Care at the University of Victoria and Child and Youth Care Programs at Vancouver Island University. Her interests are focused on the importance of communities and organizations in Child and Youth Care practice. 